\title{
Periodização imperativa: retórica, teoria e história literária
}

\author{
Imperative periodization: \\ Rhetorics, Literary Theory and Literary History
}

Matheus de Brito ${ }^{1}$

Resumo: $O$ artigo trata das implicações teórico-críticas da renovação dos estudos de retórica, com atenção para os estudos de João Hansen, Alcir Pécora, Adma Muhana, Hélio Alves e Belmiro Pereira. Numa primeira parte, discutimos esquematicamente a limitação das categorias literárias para abordagem de textos anteriores ao conceito "teórico" de literatura; numa segunda, fazemos observações para um modelo de estudo que atenda ao imperativo cognitivo da discriminação de períodos e que não recaia naquelas limitações epistêmicas. Trata-se de pensar a possibilidade de periodizar a partir dos estudos de retórica, tomando por horizonte a elaboração de uma ideia de "espaço ético-retórico" como ferramenta periodológica. (Projeto Fapesp No. 2017/11260-4.)

Palavras-chave: Retórica. Teoria da Literatura. História Literária. Poesia do século XVI.

Abstract: This paper is about the theoretical-critical implications of the renewal of rhetoric studies, with special attention to the studies of Hansen, Pécora, Muhana, Alves and Pereira. In the first part, we discuss the limitation of literary categories when dealing with texts prior to the "theoretical" concept of literature. In the second part, we draw a few thoughts towards a study model that should meet the cognitive imperative of periodological discrimination without falling into those epistemic limitations. What is intended is the possibility of periodization within a rhetorical framework, ultimately aiming at the idea of "ethical-rhetorical space" as a periodological tool.

Keywords: Rhetorics. Literary Theory. Literary History. Poesia do século XVI.

1 Pós-doutoramento IEL-UNICAMP/Fapesp - CIEC/Coimbra. 
Matheus

de Brito

Melhor mapeada que no período de incepção curricular do estudo da literatura, seria possível demonstrar que é o reconhecimento da retórica como pragmática histórica da escrita aquilo que faltava à empresa global da História Literária. Sem a necessária diferenciação conceitual, esse programa disciplinar parece muitas vezes dividido entre a estagnação de seus modelos explicativos e a profissão de vícios hermenêuticos - fenomenologismos e anacronismos -, a produtividade caduca que a discrepância entre as premissas da Teoria e da História lega à leitura no ambiente acadêmico. Se é ainda pertinente periodizar a literatura, imperativo que Vítor de Aguiar e Silva há alguns anos erguia contra as críticas ao seu "maneirismo" (2012), isto é, se tem ainda um propósito cognitivo não restrito às distorções epistêmicas geradas pelo moderno conceito de literatura e seus derivativos, uma tarefa urgente da história literária é reestruturar suas bases conceituais pela reconstrução do espaço moral-retórico, das preceptivas que regulam a produção e demais convenções no horizonte dos artefatos textuais particulares. Noutras palavras, a rearticulação da Retórica em sua base teórica pode resgatar a História Literária ao embotamento conceitual que protagoniza as narrativas de reformulação acadêmica da história literária e cultural.

\section{Categorias teórico-literárias para o estudo da poesia anterior à imprensa burguesa?}

Ao longo do século XX, como noutra ocasião expusemos (2019), um déficit epistemológico mobilizou revisões parciais - e disputas sem essa finalidade - do campo dos estudos literários. Quer considerando os ataques aos velhos moldes do ensino literário e humanístico, quer como consequência da contínua e institucionalmente amadurecida revisão a que se submete a área, hoje é patente a necessidade de um quadro de referências que atenda a um programa da história da literatura, supondo que, como matriz de hipóteses de trabalho, ela prometa algo que não sucumba junto aos universais de que se servia - como Homem, Nação, a História (em maiúsculas), e mesmo Literariedade. Essa narrativa teve sua razão de ser não nos objetos predicados literários mas nas instituições e convenções que regulam práticas de escritura e leitura na sociedade burguesa e de massas, as quais desaparecem junto ao incremento dos recursos técnicos e à reformulação do papel da Universidade. 
É possível discriminar duas séries de limitações da ideia de "literatura do século XVI", conforme sejam de ordem subjetiva ou de ordem objetiva. As subjetivas são aquelas que atinam ao conjunto de conhecimentos e expectativas com que artefatos textuais históricos são estudados e discutidos, descontando a hermenêutica trivial da leitura. É uma série de erros de método: nós temos (1) a incompatibilidade radical do conceito teórico de literatura, cujas premissas esvaziam o conteúdo empírico dos textos com o objetivo de lhes tornar disponível ao entendimento contemporâneo (DE BRITO, 2015, 2018a), numa versão estudada da leitura compreensiva ou numa espécie de inculcação memorial subreptícia, mas temos também (2) os preconceitos da história literária, que produzem programas de leitura específicos, como ao falarmos em Maneirismo, Barroco, etc. (DE BRITO, 2019). Essas categorias excedentes, que se implicam numa compreensão hermenêutica, derivam da óbvia necessidade de ajustar parâmetros de leitura a uma alteridade histórica, e, no entanto, na medida em que surgem no interior de um universo discursivo propriamente teórico e pseudocientífico, o da Teoria como disciplina, apenas adaptam o saber da história à legibilidade literária atual, destemporalizada. Disso se incumbiu, como campo de aplicação teórica e interface institucional, a história literária e seu recurso a uma narrativa global articulada sobre a unidade estilístico-temática da "época", com inflexões nacionais pouco justificáveis. Nesse sentido, a história literária surge como produção e administração de memória. Esse é o programa "espontâneo" das burguesias nacionais relativamente à reescrita da história cultural, levada a cabo com o fim de sedimentar os valores e ratificar o novo ordenamento político-jurídico. Grosso modo, são categorias produzidas nos últimos dois séculos para apreender o passado com vistas a justificar o pacto social presente, não sem lhe fazer violência e, com isso, pôr a perder o potencial crítico do processo de conhecimento. Na transmissão disciplinar, aquilo que é uma explicação diferenciadora - que é solicitada quando detectamos, por exemplo, mudanças microestruturais nos usos de um gênero poético - se converte em pressuposto compreensivo, homogeneizador. Existe um curto-circuito teórico entre o "estilo de época" e o que a hermenêutica chama de "fusão de horizontes", como se diz, que determina as modalidades presentes de leitura literária.

Quanto às limitações de ordem objetiva, elas são as conhecidas. Desde logo o fato de que a cada vez é preciso reconstruir um certo espaço comunicacional do texto, sem incorrer na falácia conforme a qual o contexto seria fator direto da representação textual e, portanto, ho- 
Matheus

de Brito

rizonte último da reconstrução histórica - e também sem descambar numa ideia gasta de "intertextualidade" cujo risco é dissolver a pragmática textual histórica num carrossel de ressonâncias culturais. Isto é, como se a nossa republiqueta literária fosse um sujeito trans-histórico, como se "Fama" no século XVI, por exemplo, fosse o mesmo que hoje chamamos (ou Pierre Bourdieu chamou) “capital simbólico". Na série objetiva, também se poderiam incluir os problemas de autoria e de fixação do cânone textual e então uma ou outra quase ninharia sobre o sentido de um vocábulo, etc. Em muitos sentidos, as limitações subjetivas são tentativas apressadas de responder a esses problemas objetivos (DE BRITO, 2018b), as quais se reproduzem e se enrijecem.

\section{Para uma discriminação de espaços ético-retóricos}

Precisamos responder duas questões: o que construir como história que sirva para a melhor compreensão geral da poesia do período sem antecipar respostas para a compreensão particular dos textos; que tipo de história literária seria aquela que não está preocupada em produzir soluções gerais a partir de um "recorte estilístico-temático" e antes visasse produzir problemas específicos - digamos, em vez de "fusão de horizontes", diferenciação cognitiva. Não é falsa a validade da construção de um período caracteristicamente literário: por um lado, é uma abordagem de resultados inegáveis, na medida em que solicita, da perspectiva do sujeito envolvido no processo, faculdades e empenhos particulares, inteligência, saber e crença na instituição literária; por outro, porque oferece uma regra básica de compreensão, a contribuição desse esforço converge com a limitação das perspectivas sobre os objetos envolvidos no processo. As perguntas do estudo literário hoje devem acompanhar a reformulação epistemológica que se passa à historiografia desde os anos 1980.

A segunda questão poderia referir-se à obra de Aguiar e Silva por vários motivos: seu Teoria não é apenas muito difundido nas universidades de língua portuguesa e espanhola, como ele mesmo manifesta um nó de conceitos e problemas institucionais mais amplos dos estudos literários e das humanidades, além de trazer um modelo de "prática normal", embora hoje estiolado ${ }^{2}$, do estudo da literatura e afinal uma doutrina

2 Por exemplo, pelas abordagens que adotam uma postura pré-teórica - apesar de se passarem por "teoria", no sentido de que são "teoria aplicada" - que, sob a bandeira do reconhecimento identitário e do espetáculo muselmanniano, proletarizam a pequena república das Letras. 
solidária dessa prática. $\mathrm{Na}$ nossa discussão, interessam três momentos de sua produção: 1) a elaboração da categoria teórico-histórica do "Maneirismo", que realiza correlativamente à produção desse manual; 2) o lugar que "Retórica" ocupa nessa teorização (AGUIAR E SILVA, 1990), de resto seguindo e ao mesmo tempo renegociando as tendências teóricas de desenraizamento disciplinar do século $\mathrm{XX}^{3}$; 3) a revisão que propõe (AGUIAR E SILVA, 2012) para aquela categoria, que não é a rigor revisão, senão a insistência na necessidade de tentar nomear "maneirista" um certo estado do sistema cultural, considerado desde seus produtos. É preciso periodizar, diz ele, seguindo o crítico Fredric Jameson; e é de se supor que só o que temos até então seria esse catálogo coalhado de um século disciplinar, a que prefixos como pré- e pós- ajudam quando o alcance descritivo dos conceitos periodológicos se mostra irrisório.

Periodização imperativa pretação como compreensão inferencial de traços estilísticos e a explicação histórica. Roger Chartier (2014) quase acidentalmente lançou o argumento, que aqui entretemos, de que a impossibilidade de constituir um arquivo sólido para a escrita anterior ao século XIX foi compensada por essa hiper-hermenêutica. A parte que compete à história consiste em dar uma narrativa à sucessão dos fenômenos textuais, estilos, no esquema escolar que hoje é de conhecimento geral. Tudo isso é consequência de um conceito de literatura talhado a partir das contemporâneas práticas de escrita, num processo a que Adma Muhana, na esteira de Leon Kossóvitch e este na do Modernismo artístico, referiu-se como “emancipação da elocução" (MUHANA, 2002). o conceito estenográfico de "emancipação", pese que tenha conotações mais amplas ${ }^{4}$, atina tanto ao processo de literaturização como ao de beletrização, respectivamente, à passagem das práticas de escrita e leitura da esfera pública para a esfera privada, com a mediação do mercado, e à incorporação de várias manifestações culturais com racionalidades específicas a um con-

3 Desestetização para Wolfgang Iser, desfilologização na senda "textual" de Roland Barthes, despositivação se solicitarmos Paul De Man, e mais alguns des- referidos por H. U. Gumbrecht (destemporalização, destotalização, desreferencialização). Uma discussão completa sobre a mudança dessas coordenadas epistemológicas foi travada em nossa tese de doutoramento (2017).

4 Emancipação da elocução ecoa a crítica modernista do século XX e nesse sentido tem alguma limitação histórica. $\mathrm{O}$ topos torna-se frágil ao destacar o processo de referentes empíricos, na medida em que pressupõe uma racionalidade tout court imanente ao processo histórico-social da cultura. Não existe uma continuidade fundamental necessária nos processos de literaturização e beletrização por que a cultura literária, considerada em seus espaços institucionais peculiares, passa. A história da literatura e de suas formas não tem protagonista. 
Matheus

de Brito

ceito determinado de "belas letras", e, portanto, acomodação daquilo que hoje não poderia senão ser visto como particularismo epocal a uma inteligibilidade universal. $\mathrm{Na}$ ida ao privado, ocorre um esvaziamento pragmático das "letras" que é por sua vez incluído no conceito teórico

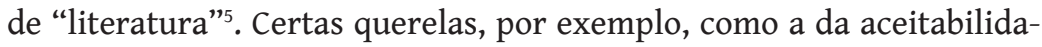
de ou não do "Maneirismo" no catálogo literário - problemática sendo sua origem nas artes plásticas, conforme contrapôs Pina Martins àquele autor - são falsos problemas enquanto o denominador comum "arte" estiver operante. Todos são conceitos etapistas cunhados no quadro de uma Teoria Literária que visava não apenas justificar a cientificidade desses saberes mas arregimentar as outras disciplinas associadas à instituição literária, mediando história e a linguística, com fins educacionais. Hoje é patente que nenhum deles oferece acesso produtivo à investigação, pois a interpretação dificilmente será ponto de partida para qualquer coisa historicamente ancorada, e, enquanto propedêutica no ensino superior, apenas dificulta a compreensão dos textos como artefatos históricos.

Seja como for, a literatura concebida como forma e estilo, no culminar desse processo, apaga as dimensões institucionais e reduz a complexidade dos eventos e forças históricas a uma narrativa epistemologicamente frouxa e metodologicamente improdutiva. A comparação entre os dois sistemas, que passou de tópico a questão teórico-preceptiva, só se tornou possível porque a produção livreira modificou o estatuto cultural da escrita e da voz. Para retomar Aguiar e Silva: essa história do estilo é um derivado de pressupostos apodíticos da literatura - quando em verdade a literatura é um conceito complexo, com uma forte carga empírica, historicamente localizável, e portanto não passível de intuição nem de derivação sintética. A impossibilidade de uma história teórica da literatura: as aproximações da história são sintéticas a posteriori, não implicam nenhuma necessidade. A forma de relatar a sucessão, a partir da equação literatura-estilo, não dá conta do desenvolvimento da pragmática da escrita e da leitura, que passa por instituições cuja complexidade não se permite reduzir ao estilo, nem

5 Um contraexemplo: a história da tornada (ou commiato) do gênero "canção" no século XIV, anterior à imprensa, passa pela preocupação com o texto como mediador da ausência do poeta no espaço social, como se infere dos comentários de Dante Alighieri, ao passo que é precisamente dessa ausência que o leitor literário do século XIX se serve no processo de literaturização. Essa herança burguesa implica não entender como o próprio teor ético dessa cultura resiste à emergência desse outro conceito de literatura. Sobre isso discutimos no artigo "As tornadas das canções, reflexões sobre um gênero" (no prelo). 
que pode ser dele deduzido. Portanto, ainda que consintamos com a autorreferência de certos movimentos - especialmente aqueles que solicitam suas próprias genealogias - não se pode falar em época senão relativamente aos marcos exteriores ao conceito teoricamente construído de literatura. Isto é, a época literária só pode ser pensada num quadro institucional em que a literatura opera de modo secundário, como derivado desse sistema. Com ou sem "maneirismos," a redução de complexidade estrutural levada a cabo com a narrativa histórico-literária que ignora a teoria e a história dos media e o justifica com injeção de filosofemas da Estética não converge num ganho funcional nem para o ensino nem para a pesquisa. A discussão é tão delicada que até usos como "emancipação" podem reverberar, por exemplo, numa questão como a de se poderíamos encontrar no processo uma espécie de crítica progressista" às doutrinas cristãs que dão liga à prePeriodização imperativa ceptiva retórica. Bem ao contrário. A fragmentação da retórica não concorreu com a constituição de uma esfera autônoma operando em paralelo à cultura de massas, mas na redução da retórica à técnica aplicada, como já o era no meio eclesiástico medieval, anterior à sua imiscuição à cultura de corte e modelos de personalidade e comportamento divulgados em manuais entre os séculos XV e XVII. Conceitualmente elaborada pelo atual nominalismo que hoje se naturaliza na consciência dos homens, o uso cotidiano de "retórica" quase sempre significa um regresso à usurpação estropiada que a oratória sacra já fizera dos auctores.

Periodizar os processos culturais enquanto instituições e atos institucionais, e não só a partir de uma fenomenologia das obras; ater-se a esse programa através de suas evidências textuais, isto é, pelo estudo da preceptiva e dos autores contemporâneos, sem dar proeminência à reconstrução dos códigos compositivos numa ótica da atual teoria e sua obsessão com a reiteração de elementos estilístico-temáticos. Assim é, em parte, como se deixa resumir a tarefa que o manual de Aguiar e Silva preparara, mas que encontra limites reais na exacerbação da validade trans-histórica da própria Teoria. Ora, se apenas abandonarmos por um momento a pretensa segurança teórica, perceberíamos que ela já não é necessária. Temos melhores condições de compreender a circulação material de textos, e com eles de tópicos e procedimentos de produção, e, dessa feita, podemos vislumbrar melhor as transformações por que as convenções da produção escrita passam. Temos também conceitos com melhor alcance epistêmico, ao menos desde que o diálogo da literatura com o estudo da história se colocou numa nova chave com os Annales (BURKE, 1992) e sobretudo a Be- 
griffsgeschichte (KOSELLECK et alii, 2016). Por fim, afastadas as condições que organizam institucionalmente o programa da história literária pós-romântica, estamos profissionalmente livres para produzir uma história crítica que não se reduza ao serviço memorial apadroado pelo Estado-Nação.

Se é preciso periodizar, para produzir conhecimento não restrito às expectativas e distorções epistêmicas geradas pelo moderno conceito de literatura e seus derivativos, a tarefa mais urgente da história literária é considerar as implicações teórico-críticas das assimetrias entre as condições de produção e circulação de poesia da imprensa pré-industrial Matheus e pré-burguesa, por um lado, e as convenções que organizam o atual sisde Brito tema literário, por outro. Essas investigações, cuja ênfase consiste na pontualidade, constroem muitas vezes seu próprio arcabouço teórico. Uma história literária que articule em sua matriz teórica a retórica deve levar em conta, deve se dedicar ao estudo desse arcabouço. Dispomos já de alguns passos fundamentais. O ensaio com que Adma Muhana introduz sua edição do tratado Poesia e Pintura ou Pintura e Poesia de Manuel Pires de Almeida (2002), por exemplo, aponta bom caminho de reconstrução da metalinguagem da época, pois fornece bases para a construção de um quadro comparativo sincrônico mais apto à compreensão da pragmática histórica da escrita. É um pouco também o que ela faz ao apresentar o "Discurso sobre o poema heroico" (2006). É preciso pensar que esses tratados não estão entremeados em questões que seriam "pontos de partida" para o século vindouro em poesia mais do que pontos de chegada de outras discussões, e, portanto, têm uma validade por assim dizer "retroativa" inequívoca. É escusado dizer que os comentários de Adma Muhana se estabelecem nesse sentido, de fazer ver na obra de Almeida o seu precedente em vez de, como outra crítica faria, procurar ver ali as prerrogativas do barroco literário, como trivialmente se faz a um outro livrinho como Corte na Aldeia (1619) de Fernão Rodrigues Lobo. Sua lição faz perceber como a tópica é regulada pelos preceitos ensinados nas escolas e mobilizados tanto na oratória sacra como na literatura em vernáculo (ou latim).

A obra de João Adolfo Hansen talvez seja aquela que mais globalmente se liga a um projeto de renovação da história literária como história de gêneros e instituições. Em verdade se escusa dizê-lo, mas o seu trabalho doutoral não apenas pôs em primeiro plano a normatividade da preceptiva e o funcionamento da poesia como encenação, no ambiente civil, de propósitos já codificados, isto é, da aplicação de diversas tópicas no espaço público, como de algum modo ele parece implicar na destruição 
do conceito de período propriamente literário, que seguiria (numa formulação brasileira) a conhecida tríade autor-obra-público, mais os eventos históricos que condicionam esses elementos. O caso de Gregório de Matos é bastante parecido ao de Luís de Camões relativamente ao cânone textual. Ora, da perspectiva da produtividade que deve andar associada ao método investigativo, a flexibilização da entidade "Autor" e a compreensão dos processos institucionais que, no fundo, reconfiguram a Autoria e o próprio conceito de obra não são uma saída "mais fácil" por desencarregar-se da filologia, mas com efeito têm mais interesse epistêmico que forçar a unidade biográfico-histórica sobre um conjunto de textos. É uma "entrada" teórica mais difícil. Digo isso, por exemplo, a respeito das confusões entre Camões e outros autores de sua geração, como Diogo Bernardes, Pêro Caminha ou Manuel de Portugal. O que é que se descobre, em Periodização imperativa verdade, ao decidir se um poema é de um e não de outro? É precisamente a familiaridade - decorrente da circulação tópica, da imitação textual e dos recursos elocutórios em voga - que precisa em si mesma ser pensada se quisermos saber mais do que a fórmula de Leodegário de Azevedo permite, que a reles semicerteza de ser o texto de autoria camoniana ou qualquer grau de probabilidade.

Um outro trabalho de igual relevância, mas que construiu o problema da inteligibilidade da comunicação literária necessariamente em outro sentido foi a tese doutoral de Alcir Pécora. Teatro do Sacramento (2008 [1995]), em linhas bem gerais, oferece uma alternativa completa e epistemicamente superior ao consórcio feito entre Teoria Literária e Linguística estruturalista, que legitima e se reproduz nos manuais literários atuais. Enquanto o foco de Hansen é uma pragmática, Pécora debruça-se sobre a dimensão por assim dizer "imanente" da escrita de António Vieira, seus conceitos e procedimentos. A unidade moral-retórica, que o autor a propósito de Vieira chama de "teológico-retórico-política" é a chave para o início de qualquer reconstrução. Entender rigorosamente o caráter desdiferenciado dessas instâncias é o remédio, é o polo oposto daquele apogeu da "emancipação da elocução". É possível introduzir aqui outro exemplo crítico para o estudo do século XVI, como o hábito de semantizar as figuras de construção sonora e o cursus, doutrina de construção da sintaxe da prosa latina que migra para o verso poético. Semantizar no sentido de interpretar o emprego de fricativas como sugestão do vento, por exemplo, ou como se a recorrência de esquemas silábicos (e.g. dois-dois-dois-quatro frequente 
Matheus

de Brito

em Camões) tivesse outra motivação que não ser simplesmente o uso. A ideia de conotação ou evocação de fenômenos simplesmente ignora uma doutrina mais fundamental sobre as semelhanças linguísticas e os seus efeitos suasórios - a eufonia não comporta significado fora do corpo da palavra, mas, ao deleitar, convence. A materialidade da palavra seria, dessa perspectiva, espiritual. Como a investigação se dedica a um caso, não parece que se construiu aí uma "teoria" de como o "sistema" funcionaria; mas, em contrapartida, o ensaísmo do autor oferece mais modelos de reconstrução. Em verdade, ele nutre resistência à ideia de um "sistema" em sentido enfático - isto é, sistema como conjunto de operações reais, de algum modo esquadrinhável por aqueles grandes conceitos (Homem, Nação) - e isso é algo que deve ser adotado por qualquer tentativa de periodizar. Em Máquina de Gêneros (2001), Pécora tece algumas considerações mínimas sobre o que não se deve fazer ao tratar-se desses objetos historicamente afastados. Essa abordagem indica pontos para que se estabeleça a ideia de período fora de um arcabouço etapista.

No quadro específico de Portugal do século XVI, são de importância as teses de Hélio Alves e Belmiro Fernandes Pereira. A investigação de Pereira (2012) mapeia a circulação das retóricas no espaço ibérico e especificamente português. Ele consegue distinguir escolas de retórica cuja homogeneização num quadro teórico produziria evidentes conflitos, como os que acabam sendo rasurados pelo conhecido trabalho de H. Lausberg (2011) sobre a retórica literária. Não bastasse a polarização que leva a cabo e a distinção de tendências no mesmo espectro quintiliano-ciceroniano, Pereira distingue um plano diacrônico muito claro ${ }^{6}$ no qual vemos as instituições operarem reconfigurações semânticas de preceitos herdados. Um exemplo crucial para entender

6 Em resumo, uma história da literatura sub species rhetoricorum poderia ser pensada, em seu espaço ético, considerando uma fase inicial em que "retórica" se restringe à oratória sacra e, por esta via, contamina a produção "goliarda" e trovadoresca. Uma fase média, em que a Retórica é ampliada e tornada comunicação de corte, associada a manuais de civilidade e profundamente vinculada ao aparelhamento do Estado. Por fim, uma fase de declínio, em que a ficção da expressão natural e imediata consagra o triunfo do gênero "médio" (lírico), por posição às formas alta e baixa (da épica e da comédia). Para uma história da literatura propriamente, novas determinações poderiam ser pensadas a partir do contexto político-econômico, jurídico e institucional em amplo sentido, na medida em que se referem a doutrinas que se destacam da retórica enquanto concepção de linguagem (e integral à civilidade da época) e se autonomizam na construção de novos sistemas de valor, com que a literatura dialogaria. Acrescente-se a essas coordenadas uma pequena história da imprensa, que se deixa pensar em fases também: a proliferação da escrita e da leitura; a posterior valorização da escrita e do saber de experiência; então a constituição da esfera pública burguesa restrita, e afinal a constituição da sociedade de massa, em que a educação compulsória instrumentaliza o acesso muito mais do que democratiza o saber. 
o "Renascimento" ibérico está no impulso secularizante associado às reformas político-institucionais da Casa de Avis, que opera a expansão do ensino da retórica mas, como mostra o autor, acaba por colocá-la numa chave jesuítica. É renegociada, por assim dizer, para atender a novas condições, como os concílios de Trento, a proliferação da escrita e da leitura alavancada pela imprensa, e uma incipiente construção da esfera pública na forma do mercado livreiro. Poderíamos listar muitos outros trabalhos recentes no espaço lusófono, mas aqui basta recapitular o que organizamos como campo de forças: 1) a consciência da urgência epistêmica daquilo que na velha teoria literária era apenas auxiliar, isto é, o fato de que as tais "metalinguagens" são provavelmente tão importantes quanto (ou mesmo mais do que) os textos cuja produção elas orientam; 2) métodos para o estudo dos quadros de uso e transforPeriodização imperativa mação dos gêneros e tópicos, bem como modelos para a reconstrução da lógica interna desse universos textuais; 3) um relativo mapeamento das principais instituições e materiais que organizam os "primórdios" da cultura literária vernácula.

Existe uma quarta articulação que se pode perspectivar rapidamente pelo trabalho de Hélio Alves (2001). Conhecido por questionar a hipertrofia camoniana no circuito literário, a forma como sua tese se dedica ao "sistema da epopeia quinhentista" põe em relevo protocolos de produção, no mesmo nível em que o faz Hansen, mas compondo um quadro diacrônico, e obriga a abandonar radicalmente o critério nacional e mesmo os espaços de vernáculo. É uma tendência também no espaço acadêmico de língua alemã, por exemplo, a de procurar os nexos entre a poesia neolatina e literatura em vernáculo, o mais evidente deles sendo o fato de que o latim era a língua da elite cultural e, portanto, do ensino ${ }^{7}$. Quanto ao trabalho de Alves, a virtude está sobretudo em como abre mão de categorias explicativas de natureza compreensiva, como a do Maneirismo e Barroco ao tratar da diacronia; o autor, porém, não produz uma história, como é preciso fazer, da preceptiva poética. Essa é uma atitude prometida numa obra como a de Maria do Céu Fraga sobre Os géneros maiores na poesia lírica de Camões

7 Os mais interessantes trabalhos parecem hoje aqueles produzidos na Alemanha, na Áustria e na Bélgica, desde o volumoso Historisches Wörterbuch der Rhetorik, organizado por Kalivoda e Robling em 1990. Vale ressaltar a proximidade desse projeto com o da "história dos conceitos", Historisches Wörterbuch der Philosophie (1970 a 2007). O espaço acadêmico germanófono tem conhecido muitos trabalhos de caráter "teórico" sobre a preceptiva retórica, p.ex., à volta da reconstrução de operadores pragmáticos ou conceitos culturais como "poeta" e "poesia". 
Matheus

de Brito

(2003), que lhe é posterior, ou que é frustrada no subtítulo do conhecido Retórica e Teorização Literária em Portugal (2008) de autoria de Aníbal Pinto de Castro, já bem anterior. Enfim, há muitos trabalhos, mas parece ainda faltar um esforço coerente, programático, de reconstrução que permita pensar a diacronia dos preceitos e tópicos da cultura letrada ibérica anterior à imprensa burguesa.

A modo de conclusão, resta-nos insistir que é hoje um imperativo esquecer as categorias periodológicas usuais, abrir mão do princípio hermenêutico textual e orientar as definições da Teoria na contramão de seu conceito estético-teórico de literatura. Só isso permite operar a reconstrução da semântica histórica da comunicação, pautada nas preceptivas retórico-poetológicas. Não será essa uma história de estilos que representam quadros espirituais da cultura, oferecendo representações de uma realidade que nos é sempre, e de modo encarecedor, "atual" em virtude do erro epistêmico de que se parte, mas uma história de convenções que coordenam processos, dos quais a cultura literária é um subprocesso, e relativamente ao qual houve uma interrupção da continuidade histórica. É preciso supor a interrupção da continuidade se queremos imaginar que o passado tem mais a oferecer do que ser simplesmente servil às expectativas imediatas do presente ou mera reprodução de um discurso humanístico cujas premissas desapareceram.

\section{REFERÊNCIAS}

AGUIAR E SILVA, Vítor Manuel de. Para a revisão do conceito de Maneirismo. In: FERRO, M.; FRAGA, M. DO C.; MARTINS, J. C. DE O. (Org.). Camões e os Contemporâneos. Coimbra / Ponta Delgada / Braga: Centro Interuniversitário de Estudos Camonianos (CIEC) / Universidade dos Açores (DLLM) / UCP, 2012. .

Teoria e Metodologia Literárias. Lisboa: Universidade Aberta, 1990.

ALMEIDA, Manuel Pires de e MUHANA, Adma Fadul. Discurso sobre o poema heróico. Revista Eletrônica de Estudos Literários, v. 2, n. 2, p. 1-23, 2006. 
ALVES, Hélio J. S. Camões, Corte-Real e o sistema da épica quinhentista. Coimbra: Centro Interuniversitário de Estudos Camonianos, 2001.

BURKE, Peter. A Revolução Francesa da Historiografia. São Paulo: Editora UNESP, 1992.

CASTRO, Aníbal Pinto de. Retórica e teorização literária em Portugal: do Humanismo ao Neoclassicismo. Lisboa: Imprensa Nacional-Casa da Moeda, 2008.

Periodização imperativa

CHARTIER, Roger. A mão do autor e a mente do editor. São Paulo: UNESP, 2014.

DE BRITO, Matheus. Semiótica ou Estética: considerações sobre a epistemologia das Letras. Revista Estudos Linguísticos, v. 44, n. 3, p. 1409-1419, 2015. Disponível em: <http://revistas.gel.org.br/ estudos-linguisticos/article/view/1066>.

Materialidade e contingência: contribuições à reflexão estética nos estudos literários. 2017. Universidade de Coimbra / Universidade Estadual de Campians, 2017.

Camões e a Civilização do Comércio? Studia Universitatis Babes-Bolyay. Philologia, v. LXII, n. 4, p. 139-150, 2018a.

Para uma teoria da burrice. Literatura: teoría, historia, crítica, v. 20, n. 2, 2018b.

A Teoria e a História da Literatura, e o Maneirismo. [No prelo.]

FRAGA, Maria do Céu. Os Géneros Maiores na Poesia Lírica de Camões. Coimbra: Centro Interuniversitário de Estudos Camonianos, 2003.

KOSELLECK, Reinhart et alii. O conceito de História. Belo Horizonte: Autêntica, 2016. 
LAUSBERG, Heinrich. Elementos de Retórica Literária. Tradução

R. M. Rosado Fernandes. Lisboa: Calouste Gulbenkian, 2011.

MUHANA, Adma Fadul. Poesia e Pintura ou Pintura e Poesia: Tratado Seiscentista de Manuel Pires de Almeida. São Paulo: EDUSP, 2002.

PÉCORA, Alcir. Máquina de Gêneros. São Paulo: EDUSP, 2001.

Teatro do Sacramento. Campinas: Unicamp, 2008.

Matheus

de Brito PEREIRA, Belmiro Fernandes. Retórica e eloquência em Portugal na época do Renascimento. Lisboa: Imprensa Nacional-Casa da 318 Moeda, 2012. 